\title{
BULLD0G,A Useful Vascular Occlusion Tourniquet in Laparoscopic Liver Resection
}

\author{
Liang He, Weixiang Li, Dachen Zhou, Lei Wang, Hui Hou*and Xiaoping Geng* \\ Department of Hepatobiliary surgery, The Second Hospital of Anhui Medical University, PR China
}

*Corresponding author: Xiaoping Geng and Hui Hou, Department of Hepatobiliary surgery, The Second Hospital of Anhui Medical

University, 678Furong Road, Hefei, Anhui 230601, PR China

\section{ARTICLE INFO}

Received: 蔧 June 21, 2020

Published: 幽 July 15, 2020

Citation: Liang He, Weixiang Li, Dachen Zhou, Lei Wang, Hui Hou, Xiaoping Geng. BULLDOG,A Useful Vascular Occlusion Tourniquet in Laparoscopic Liver Resection. Biomed J Sci \& Tech Res 28(5)-2020. BJSTR. MS.ID.004718.

Keywords: Laparoscopic Hepatectomy;Bulldog; Vascular Occlusion; Tourniquet

\section{ABSTRACT}

Aim: To compare the clinical effect of modified Pringle with traditional Pringle for vascular occlusion during laparoscopic hepatectomy.

Methods:110 patients were retrospectively investigated in this research from December 2014 to January 2019 in the second hospital of An Hui Medical University, who underwent laparoscopic liver resection using bulldog (modified group, $n=54$ ) and cotton tourniquet (traditional group, $\mathrm{n}=56$ ) for blocking the liver inflow-blood. Intraoperative blood loss, duration of the operation time, clamping time, postoperative outcomes were analyzed.

Results: All the operations were accomplished successfully without conversion to laparotomy, perioperative period clinical date were calculated. Intraoperative operative time, blood loss and resection sections had no statistical significance, but the clamping and declamping time $(36.2 \pm 5.6$ vs.277.3 $\pm 88.4 \mathrm{~s}, \mathrm{p}<0.001)$ was significantly shorter in the bulldog group. ALB, ALT, AST and TBIL had no statistical differences in PODs 1and 3, but POD 5 ALT $(71.0 \pm 46.8 v s .105 .8 \pm 61.7 \mathrm{IU} / \mathrm{L} \mathrm{p}=0.018)$ and AST(72.8 \pm 39.7 vs.100.2 $\pm 16.7 \mathrm{IU} / \mathrm{L} \mathrm{p}=0.028)$. The postoperative hospital stay( $7.02 \pm 1.56 \mathrm{vs} .8 .50 \pm 2.35$ days $p=0.026$ ) in bulldog group were lower than cotton group and differences had statistical significance. The C-reactive protein levels were significantly higher in the traditional group than in the modified group on POD $3(46.3 \pm 19.2$ vs.57.7 $\pm 23.9 \mathrm{mg} / \mathrm{L}$ $\mathrm{p}=0.019)$, and POD5 (13.3 $\pm 4.2 \mathrm{vs} .17 .5 \pm 7.3 \mathrm{mg} / \mathrm{L} \mathrm{p}=0.001)$. There were 8 postoperative complications occurred in cotton group, while there was 5 in Bulldog group, All patients with complications were discharged after adequate drainage and symptomatic treatment.

Conlusion: Bulldog is an effectively performed approach for vascular occlusion during laparoscopic hepatectomy than traditional Pringle manuever.

\section{Introduction}

Since the Louisville Statement in 2009, the use of laparoscopic liver resection (LLR) had gradually increased in recent years [1,2]. LLR was used for Benign tumors located at the Surface lateral with solitary lesions of $5 \mathrm{~cm}$ or less, located in liver segments 2 to 6. that could be resected more easily than segment VII VIII[3-7]. With the update of surgical instruments and the accumulation of surgeon experience, LLR has been expanded for Hepatocellular carcinoma treatment, major liver resections, complex hepatectomy and donor hepatectomies by experienced staff[8]. In 2016[9], the first Asia Pacific consensus meeting on HCC was held in conjunction with the 7th Asia-Pacific Primary Liver Cancer Expert Meeting in Hong Kong to declare the advantage of LH is Less intraoperative bleeding and faster postoperative liver function recovery if the procedure is performed by experienced surgeons. Laparoscopic major hepatectomy for HCC remained a challenging technique and should only be performed by experienced surgeons. However, 
postoperative mortality, morbility and recovery of liver function are associated with major blood loss[10] which is always the main cause of conversion to laparotomy[11] and remains a challenge for surgeons[12,13]. Pringle[14]first described the method to arrest the hepatic hemorrhage by compression of the porta hepatis and this procedure was widely spread as well as the in laparoscopic field currently. Here, we described a new modified of Pringle maneuver using Bulldog to block vascular during LLR, and compared its effects with traditional pringle maneuver.

\section{Methods}

\section{Patient Population}

From Dec, 2014 to Jan, 2019,200 patients underwent LLR in our department, at the 2nd hospital of Anhui medical university and in which 110 patients underwent LLR with vascular occlusion. There were 54 patients in the Bulldog group, and 56 patients in the traditional group.38 femail and 72 mail participants were included in this study, with the mean age of $(56.1 \pm 10.9$ and $60.0 \pm 8.8)$ years old, Respectively. Clinical characteristics of patients, were summarized in Table 1.

Table 1: Patient basis characteristics (mean $\pm S D$ ).

\section{Inclusion and Exclusion Criteria}

This study has been approved by the ethics committee of The Second Hospital of Anhui Medical University. Each participant in the study provided written informed consent. The inclusion criteria including:

a. All the participants were corresponded with the application of LLR, according to the Louisville Statement $[2,8]$ and underwentlaparoscopic liver resection.

b. The bulldog and cotton tape were applied in operation.

c. The tumor did not invade main vessels.

d. Pringle maneuver clamping time was unified as $15 \mathrm{~min}$ every time and right Glission pedicles was clamped only once. The LLR was not limited to the disease, including benign tumor, malignance tumor, calculus disease and others (Table 1). The cases that did not agree with the inclusion criteria were excluded.

\begin{tabular}{|c|c|c|c|c|}
\hline \multirow{2}{*}{ Patient Group Characteristic } & \multirow{2}{*}{$\begin{array}{l}\text { Bulldog } \\
(n=54)\end{array}$} & \multirow{2}{*}{$\begin{array}{l}\text { Cotton } \\
(n=56)\end{array}$} & $\mathrm{T}(\mathrm{x} 2)$ & $\mathbf{P}$ \\
\hline & & & \multicolumn{2}{|c|}{ value } \\
\hline Age(years) & $56.1 \pm 10.9$ & $60.0 \pm 8.8$ & 2.683 & 0.104 \\
\hline Gender(male/female) ${ }^{\mathrm{a}}$ & $39 / 15$ & $33 / 23$ & 2.149 & 0.143 \\
\hline HBV & 42 & 47 & 0.673 & 0.412 \\
\hline $\mathrm{HCV}$ & 3 & 2 & 0.249 & 0.617 \\
\hline $\mathrm{AFP}$ & & & 0.015 & 0.903 \\
\hline$>7(\mathrm{ng} / \mathrm{ml})$ & 38 & 40 & & \\
\hline$<7(\mathrm{ng} / \mathrm{ml})$ & 16 & 16 & & \\
\hline ALT & $44.2 \pm 33.1$ & $40.2 \pm 38.7$ & 0.585 & 0.560 \\
\hline AST & $40.2 \pm 23.4$ & $39.4 \pm 27.4$ & 0.410 & 0.523 \\
\hline ALB & $38.7 \pm 7.9$ & $38.5 \pm 4.6$ & 0.143 & 0.887 \\
\hline TBIL(umol/l) & $16.5 \pm 9.5$ & $16.9 \pm 8.1$ & 0.01 & 0.972 \\
\hline $\mathrm{CRP}(\mathrm{mg} / \mathrm{L})$ & $4.1 \pm 2.2$ & $4.5 \pm 2.7$ & 0.90 & 0.370 \\
\hline Liver cirrhosis & 44 & 46 & 0.008 & 0.928 \\
\hline Child-Pugh(A/B) & $52 / 2$ & $55 / 1$ & 0.381 & 0.537 \\
\hline Diagnoses & & & 0.388 & 0.824 \\
\hline Hepatic cancer & 39 & 42 & & \\
\hline hepatic benign tumor & 10 & 8 & & \\
\hline Calculusof intrahepatic duct & 5 & 6 & & \\
\hline
\end{tabular}

Note: SD: standard deviation. AFP: Alpha fetoprotein ALT: alanine aminotransferase. AST: aspartate aminotransferase. TBIL: serum total bilirubin.HBV: hepatitis B virus.HCV:hepatitis C virus. CRP: C-reactive protein

\section{Surgical Procedure}

General anesthesia was performed routinely. The patients were placed in the supine position, and a $10-\mathrm{mm}$ trocar was placed $2 \mathrm{~cm}$ right the umbilicus under direct vision(Figure1). Intraabdominal pressure was established and maintained around $14 \mathrm{mmHg}$ and Central Venous Pressure(CVP) was set below five $\mathrm{cmH}_{2} \mathrm{O}$ [15]. The rest four trocars were placed based according to the tumor position. Intraoperative laparoscopic ultrasound was used as a requirement. 
Liver parenchymal transection was performed using a combination of a harmonic scalpel, ultrasonic dissector (Cavitron), and bipolar forceps. For cases with Pringle maneuver, the cotton and bulldog method were applied. In the bulldog group, we routinely exploredthe abdominal cavity, dissociated the mucosal tissue around the hepatoduodenal ligament, exposed the hepatic portal as well as the right Glissionean pedicles. Bulldog was delivered into the abdominal cavity with the matched forceps through the 12-mm trocar to block hepatoduodenal ligament or the right Glissionean pedicles (Figure 2) to block the hepatic inflow. While, in the cotton clamping group, we need another 5 -mm port trocar, which should be positioned in proper place to ensure the encircle of the hepatoduodenal ligament, A forceps went through the the hepatic pedicle and an $80-\mathrm{cm}$ cotton tape was placed around it. Then, the ends of the cotton tape were pulled out through the 5-mm trocar port, and a tube was pushed inside the abdominal cavity close to the hepatic pedicle, and was fastened by pulling cotton tape through the tube [16](Figure 3).
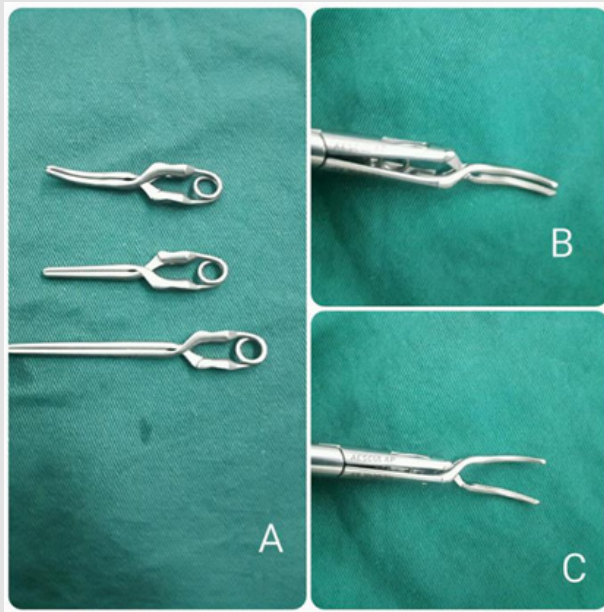

Figure 1: Bulldog

A. The different lengths of Bulldog, the longer was used to pringle manuever, the other were used to the right Glission pedicles, the unique curved design fits better with the baseline than ordinary straight clamp, further ensuring complete vascular occlusion.

B. The matched forceps,non-working status.

C. Working status.

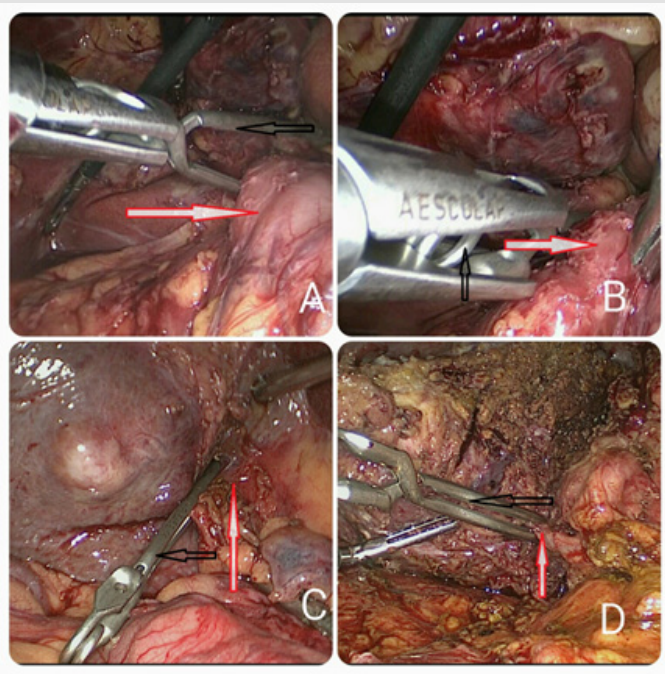

Figure 2: The Bulldog in intraoperative pictures.

Note: A and B: red arrows represent hepatoduodenal ligament, C and D: red arrows represent the anatomized right Glission pedicle. A: The forceps hold the Bulldog into the abdominal cavity and start to infibulate the hepatoduodenal ligament, it is easy to operate. B:the bulldog can securely clap the hepatoduodenal ligament. C and D: Bulldog was clamped the right Glission pedicles. All the black arrows represent bulldog. 

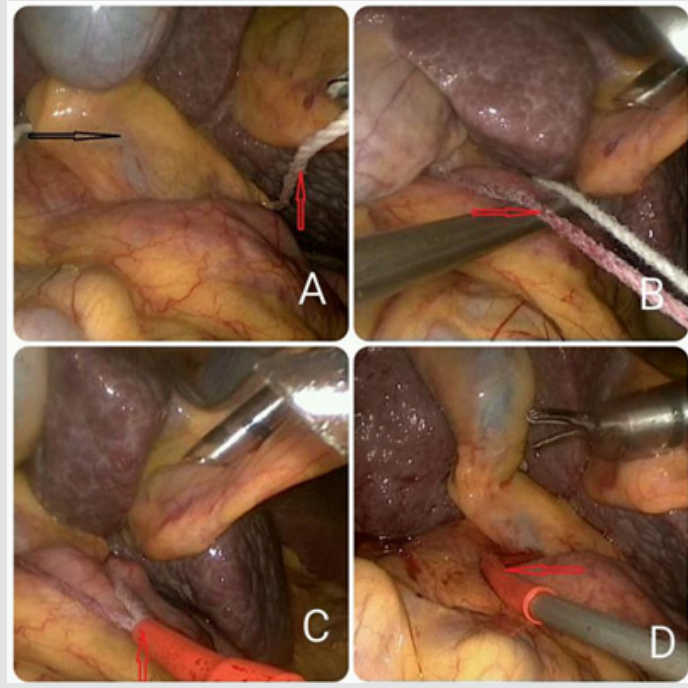

Figure 3: The cotton in intraoperative pictures.

Note: This picture show the process of clamping with cotton during laparoscopic hepatectomy through Extracorporeal methods. A:the cotton was passed behind the hepatoduodenal ligament,B:fasten the cotton.C and D: the tube was used to encircle the hepatoduodenal ligament,and kept the end of the tape out,and fasten by pulling tape through the tube.

\section{Outcomes}

All the patients underwent the operation by one team and received the same postoperative care. The postoperative complications were recorded and analyzed.The CRP and liver functionmarkers including ALT,AST,TBIL and ALB were checked at first, third and fifth day after liver resection as well as the postoperative duration.

\section{Statistical Methods}

Data were analyzed with SPSS 17.0 (IBM Corporation, NY, USA). Continuous variables weredescribed as mean \pm standard deviation(SD) and subjected to Student's t test. The $\mathrm{x} 2$ test (with continuity corrected $x^{2}$ if the expected count was $<5$ ) or the Fisher exact test was appropriate for categorical data. A p value of $<0.05$ was set as statistically significant.

\section{Introperative Clinical Outcomes}

Table 2: PaIntraoperative detail patients(mean $\pm S D)$.

\begin{tabular}{|c|c|c|c|c|}
\hline & Bulldog(54) & $\operatorname{cotton}(56)$ & $\mathrm{T}\left(\mathrm{x}^{2}\right)$ & P Value \\
\hline Type of resection ,n & & & 7.168 & 0.127 \\
\hline Segment II+III & 2 & 3 & 0.173 & 0.677 \\
\hline Segment II+III+IV & 10 & 18 & 2.689 & 0.101 \\
\hline Segment V+VIII & 13 & 12 & 0.11 & 0.741 \\
\hline Segment VI+VII & 18 & 17 & 0.112 & 0.738 \\
\hline Segment V,VI,VII,VIII & 11 & 6 & 1.962 & 0.161 \\
\hline Intraoperative blood loss (ml) & $371.8 \pm 216.2$ & $411.3 \pm 216$ & 0.958 & 0.34 \\
\hline Left segment(ml) & $179.2 \pm 39.6$ & $196.9 \pm 73.7$ & 0.768 & 0.448 \\
\hline Right segment(mil) & $430.4 \pm 209.5$ & $532.8 \pm 178.9$ & 2.279 & 0.025 \\
\hline Patients transfused & $4(7.4 \%)$ & $8(14.2 \%)$ & 1.338 & 0.247 \\
\hline Clamping time (s) & $36.2 \pm 5.6216 .9 \pm 68.2$ & $277.3 \pm 88.4$ & 1.76 & 0 \\
\hline
\end{tabular}




\begin{tabular}{|c|c|c|c|c|}
\hline Operation time (min) & $161.3 .4 \pm 68.9$ & $236.4 \pm 71.2$ & 1.472 & 0.144 \\
\hline Left segment(min) $^{\prime}$ & $241.7 \pm 54.7$ & $172.2 \pm 32.9$ & 0.616 & 0.542 \\
\hline Right segment(min) & $85.1 \pm 23.6$ & $279.7 \pm 51.9$ & 1.956 & 0.003 \\
\hline Liver resection time(min) $^{\text {The blocking numbers }}{ }^{\mathrm{b}}$ & 126 & $97.5 \pm 21.3$ & 6.614 & 0.306 \\
\hline -Left segment(n) $^{\text {-Right segment(n) }}$ & 20 & 156 & & 0.01 \\
\hline
\end{tabular}

Note: SD: standard deviation. a: clamping time represent the overall time consuming by clamping the tourniquet which obtained from surgery video. b: the summary times of blocking. Segment V,VI,VII,VIII: including V,VI,VII,VIII and right hepatectomy.

Introperative clinical outcomes are summarized in Table 2. The number of bulldog group blocked the hepatic vessels was 126 and the cotton group was 156. No statistical differences were observed in the type of liver resection, the duration operation time and blood loss , but the clamping time was significantly shorter in the bulldog group(36.2 \pm 5.6 vs.277.3 $\pm 88.4 \mathrm{~s}, \mathrm{p}<0.001)$.

\section{Postoperative Clinical Outcomes}

The liver function on PODs 1,3 and 5 as reflected by the postoperative changes of ALT,AST, TBILand PT were shown in Table3, the mean POD 1 PT,ALT,AST and TBIL showed no statistic differences in POD1 and POD3, but POD5 ALT (71.0 $\pm 46.8 v$ v.105.8 \pm 61.7 IU/L $\mathrm{p}=0.018)$ and AST(72.8 \pm 39.7 vs.100.2 $\pm 16.7 \mathrm{IU} / \mathrm{L}, \mathrm{p}=0.028)$. The postoperative hospital duration $(7.02 \pm 1.56$ vs.8.50 \pm 2.35 days, $\mathrm{p}=0.026$ ) in the bulldog group was lower than the cotton group and differences had statistical significance. The C-reactive protein levels were significantly higher in the traditional group than in the modified group on POD $3(46.3 \pm 19.2$ vs. $57.7 \pm 23.9 \mathrm{mg} / \mathrm{L}$ $\mathrm{p}=0.019)$, and POD5 (13.3 \pm 4.2 vs.17.5 $\pm 7.3 \mathrm{mg} / \mathrm{L} \mathrm{p}=0.001)$. All of the manipulations are easily and quickly using Bulldog, There were eight postoperative complications occurred in cotton group, while there was five in Bulldog group, which were disappeared by drainage and anti-infection treatment for five-nine days.

Table 3: Postoperative clinical course(mean $\pm S D)$.

\begin{tabular}{|c|c|c|c|c|}
\hline & Bulldog(n=54) & Cotton(n=56) & $\mathrm{T}$ & P-value \\
\hline PMT & $0(0)$ & $0(0)$ & & \\
\hline PMB & $5(9.26 \%)$ & $8(14.3 \%)$ & & \\
\hline Hemorrhage & $0(0)$ & $0(0)$ & & \\
\hline Biliary fistula & $1(1.85 \%)$ & $2(3.57 \%)$ & & \\
\hline Celiac infection & $1(1.85 \%)$ & $1(1.79 \%)$ & & \\
\hline Peritoneal effusion & $1(1.85 \%)$ & $1(1.79 \%)$ & & \\
\hline Pleural effusion & $0(0)$ & $1(1.79 \%)$ & & \\
\hline Pulmonary infection & $1(1.85 \%)$ & $1(1.79 \%)$ & & \\
\hline Venous hrombosis & $1(1.85 \%)$ & $2(3.57 \%)$ & & \\
\hline \multicolumn{5}{|c|}{ POD1 } \\
\hline ALB & $30.9 \pm 4.91$ & $31.5 \pm 4.53$ & 0.156 & 0.693 \\
\hline ALT(IU/L) & $346.9 \pm 267.2$ & $387.8 \pm 276.0$ & 1.089 & 0.299 \\
\hline AST(IU/L) & $375.7 .9 \pm 284.1$ & $413.6 \pm 257.8$ & 0.001 & 0.976 \\
\hline TBIL(umol/l) & $27.1 \pm 14.25$ & $28.2 \pm 13.3$ & 0.109 & 0.742 \\
\hline $\mathrm{CRP}(\mathrm{mg} / \mathrm{l})$ & $73.7 \pm 19.8$ & $75.9 \pm 27.5$ & 0.564 & 0.454 \\
\hline \multicolumn{5}{|c|}{ POD3 } \\
\hline ALB & $34.5 \pm 4.8$ & $34.0 \pm 3.5$ & 8.269 & 0.445 \\
\hline ALT(IU/L) & $192.2 \pm 109.4$ & $233.2 \pm 146.6$ & 3.149 & 0.079 \\
\hline AST(IU/L) & $182.7 \pm 138.1$ & $230.9 \pm 177.8$ & 3.313 & 0.072 \\
\hline TBIL(umol/l) & $23.5 \pm 10.9$ & $27.2 \pm 11.4$ & 0.936 & 0.336 \\
\hline $\mathrm{CRP}(\mathrm{mg} / \mathrm{l})$ & $46.3 \pm 19.2$ & $57.7 \pm 23.9$ & 0.811 & 0.019 \\
\hline \multicolumn{5}{|c|}{ POD5 } \\
\hline ALB & $36.1 \pm 4.74$ & $35.6 \pm 3.87$ & 1.167 & 0.282 \\
\hline ALT(IU/L) & $71.0 \pm 46.8$ & $105.8 \pm 61.7$ & 5.787 & 0.018 \\
\hline AST(IU/L) & $72.8 \pm 39.7$ & $100.2 \pm 16.7$ & 4.979 & 0.028 \\
\hline
\end{tabular}




\begin{tabular}{|c|c|c|c|c|}
\hline TBIL(umol/l) & $17.43 \pm 8.03$ & $20.9 \pm 9.2$ & 0.226 & 0.636 \\
\hline CRP(mg/l) & $13.3 \pm 4.2$ & $17.5 \pm 7.3$ & 3.579 & 0.001 \\
\hline PHSb(days) & $7.02 \pm 1.56$ & $8.5 \pm 2.35$ & 5.116 & 0.026 \\
\hline
\end{tabular}

Note:PMT: postoperative mortality, PMB: postoperative morbility. POD: postoperative day.PT: prothrombin time. NS: no specific. ALB: albumin ALT: alanine aminotransferase. AST: aspartate aminotransferase.

PHS: postoperative hospital stay. TBIL :serum total bilirubin. SD : standard deviation. CRP: C-reactive protein.

\section{Discussion}

With the innovations of laparoscopic technique and specialized equipment, laparoscopic liver resection became the dominating resection surgery approach[17]. From Dec of 2014, laparoscopic hepatectomy was firstly carried out in our department, extracorporeal[16,18,19] Pringle maneuver has been applied in most laparoscopic liver resections which need to block the hepatic inflow, the cotton tape was frequently applied[20]. Also, there were many novel devices, Shin-ichiro[21] recommended the smooth and effective way of Biliary Scope for Pringle's Maneuver in laparoscopic hepatectomy in 2007. Next year, Akihiro[22] investigated 32 consecutive patients with Endo Retract Maxi for Pringle maneuver during laparoscopic hepatectomy and Dua MM used umbilical tape[23] in 2015. We used to block the hepatic inflow by extracorporeal Pringle maneuver method with cotton tape5 for its validity, softness and safe for vessel protection, but it was always tricky for clamping in a two-dimensional view to encircle the hepatoduodenal ligament, and it delayed operation time for unexperienced surgeon. Bulldog has been widely used in urinary surgery[24,25] for vascular occlusion, In gynecology, Yang[26] Express the bulldog clamp is a well crossover clamp with serrated blades that effectively occlude vessels without slippage or significant crush injury, is the laparoscopic instrument for minimizing blood loss during the surgical procedure. But bulldog in hepatic surgery has rarely been mentioned, this is the first report to formally demonstrate the clinical application in hepatic surgery. in this study, we compared the cotton and the bulldog for vascular occlusion during laparoscopic hepatectomy, all the tourniquets were clamped successfully, in spite of the position of the patient or the presence of cirrhosis.

The intermittent Pringle maneuver blocking time was consistently $15 \mathrm{~min}$ no matter which way and 5-min release periods. all the right Glissionean pedicles were clamped only once to assure that two clinical data were comparable. The comparison of clamping and declamping the tourniquet is indispensable. after all, we prefer to the laparoscopic instruments which are useful and easy to implement . Ischemic reperfusion injury and amount of blood loss play a significant role in liver function, which was reflected by the clamping time and blood loss. In subgroup of operation time, the results show us that the operation time of the right segment in bulldog group was shorter $(\mathrm{p}=0.003)$. There is no statistical difference occurred in left segments, which suggested that the Bulldog's superiority stands out in right segments, especially located tumors involving segments 7, and 8[27]where procedures were considered the most difficult. When we compared to the clamping numbers, we found that the mean proportion of every procedure in left segments was 1.67 and 2.1, and which in the right segments were 2.52 and 3.17, which demonstrated that Ischemic reperfusion injury was worse in the traditional group $(\mathrm{p}=0.010)$.

While postoperative liver functions were reflected by the postoperative TBIL,ALB, ALT and AST levels. When the ALT and AST levels on POD 5, the bulldog group showed significantly lower ALT and AST levels than the cotton group, which reflected the earlier recovery of postoperative liver function, The bulldog group was associated with lower ALT and AST levels on PODs 1 and 3, but no significant differences were observed between the two groups, which may be caused by high proportion right segment hepatectomies, which also could be caused by the variance in ALT and AST levels on PODs 1 and 3 and the statistical variation of small sample size. Additional, CRP reveals a consistent response to surgical damage and evaluates the overall acute-phase reaction. Postoperative levels of CRP rise at 4-12 h, peak at 24-72 h and return to baseline around 2 weeks[28]. In our study, the level of CRP was significantly lower in the bulldog group comparing to the traditional Pringle group, which demonstrated less surgical trauma in the bulldog group. and the postoperative hospital stay was lower. Throughout most of the data, even though most outcomes were calculated with no statistical differences, outcomes from intraoperative or postoperative in bulldog group were better than the cotton tape group.

\section{Advantages and Disadvantages}

Cotton with Extracorporeal Pringle maneuver needs another incision[29], and the tourniquet need to vary following the tumor location to encircle easily. Besides, it is difficult to clamp with laparoscopic instruments and easy to enwind. Most procedures required at least once blocking, so the cotton process in laparoscopic context were mess around for freshmen. The postoperative clinical outcomes also showed more complications occurred in traditional group. How about the Bulldog? First, it did not have any effect on operation field and easy to operate with low requirements of laparoscopic technique with less time and promoted the procedure. Second, small teeth covered the bulldog surface which can clamp the hepatoduodenal ligament or the right Glissionean pedicles toughly and no one creep down to guarantee the security. Third , took it out without any difficulties when you need to loosen it to avoid the overlong ischemia reperfusion injury, and reused it after 
disinfection. Fourth, its special material and easy to manipulate may reduce the risk of injury for vascular[30], bile duct and surrounding parenchyma which contributed to the earlier recovery of postoperative liver function. The last but not the least, They have less incidence of postoperative complications of 54 patients.

\section{Conclusion}

Bulldog for vascular occlusion is effective and time saving during laparoscopic liver resection with 54 patients than the traditional group, maybe the number is limited and more information are needed to witness its superiority, but we believe bulldog will be effectively performed approach for suitable patients undergoing laparoscopic liver resection with the advantages of simpleness, security and effectiveness.

\section{Acknowledgement}

Liang He and Weixiang Li are co-first authors, Xiaoping Geng and Hui Hou are co-corresponding authors. The authors would sincerely thank the reviewers and editors for critically reviewing and editing this manuscript. This manuscript is being submitted as an original article. This manuscript has not been presented on a society or meeting before.

\section{Funding}

The study was supported by grants from Anhui Medical University Science Foundation(2015hhjh05).

\section{Conflicts of Interest}

The authors declare that they have no conflicts of interest.

\section{References}

1. He J, Amini N, Spolverato G, Hirose K, Makary M, et al. (2015) National trends with a laparoscopic liver resection: results from a populationbased analysis. HPB 17(10): 919-926.

2. Buell JF, Cherqui D, Geller DA, O'Rourke N, Iannitti D, et al. (2009) The international position on laparoscopic liver surgery: The Louisville Statement, 2008. Annals of surgery 250(5): 825-830.

3. Ikeda T, Toshima T, Harimoto N, Yamashita Y, Ikegami T, et al. (2014) Laparoscopic liver resection in the semiprone position for tumors in the anterosuperior and posterior segments, using a novel dual-handling technique and bipolar irrigation system. Surg Endosc 28(8): 2484-2492.

4. Dagher I, Proske JM, Carloni A, Richa H, Tranchart H, et al. (2007) Laparoscopic liver resection: results for 70 patients. Surg Endosc 21(4): 619-624.

5. Coelho FF, Kruger JAP, Fonseca GM, Araújo RL, Jeismann VB, et al. (2017) Laparoscopic liver resection: Experience based guidelines. World J Gastrointest Surg 8(1): 5-26.

6. Park JS, Han HS, Hwang DW, Yoon YS, Cho JY, et al. (2012) Current status of laparoscopic liver resection in Korea. J Korean Med Sci 2(7): 767-771.

7. Hwang DW, Han HS, Yoon YS, Cho JY, Kwon Y, et al. (2013) Laparoscopic major liver resection in Korea: a multicenter study. J Hepatobiliary Pancreat Sci 20(2): 125-130.

8. Wakabayashi G, Cherqui D, Geller DA (2015) Recommendations for laparoscopic liver resection: a report from the second international consensus conference held in Morioka. Annals of surgery 261(4): 619629.
9. Cheung TT, Han HS, She WH (2018) The Asia Pacific Consensus Statement on Laparoscopic Liver Resection for Hepatocellular Carcinoma: A Report from the 7th Asia-Pacific Primary Liver Cancer Expert Meeting Held in Hong Kong. Liver Cancer 7(1): 28-39.

10. Katz SC, Shia J, Liau KH, Gonen M, Ruo L, et al. (2009) Operative blood loss independently predicts recurrence and survival after resection of hepatocellular carcinoma.Ann Surg 249(4): 617-623.

11. Troisi RI, Montalti R, Van Limmen JG, Cavaniglia D, Reyntjens K, et al. (2014) Risk factors and management of conversions to an open approach in laparoscopic liver resection: analysis of 265 consecutive cases. HPB (Oxford) 16(1): 75-82.

12. Kawaguchi Y, Nomi T, Mal F, Kokudo N, Gayet B, et al. (2016) Hemorrhage control for laparoscopic hepatectomy: technical details and predictive factors for intraoperative blood loss. Surg Endosc 30(6): 2543-2551.

13. Coelho FF, Kruger JA, Fonseca GM, Araújo RL, Jeismann VB, et al. (2016) Laparoscopic liver resection: Experience based guidelines. World J Gastrointest Surg 8(1): 5-26.

14. Pringle J (1908) V Notes on the Arrest of Hepatic Hemorrhage Due to Trauma. Ann Surg 48: 541-549.

15. Otsuka Y, Katagiri T, Ishii J, Maeda T, Kubota Y, et al. (2013) Review Gas embolism in laparoscopic hepatectomy: what is the optimal pneumoperitoneal pressure for laparoscopicmajor hepatectomy?. Hepatobiliary Pancreat Sci 20: 137-140.

16. Rotellar F, Pardo F, Bueno A, Martí Cruchaga P, Zozaya G (2012) Extracorporeal tourniquet method for intermittent hepatic pedicle clamping during laparoscopic liver surgery: an easy, cheap, and effective technique.Langenbecks Arch Surg 397(3): 481-485.

17. Ciria R, Cherqui D, Geller DA, Briceno J, Wakabayashi G (2016) Comparative Short-term Benefits of Laparoscopic Liver Resection: 9000 Cases and Climbing. Ann Surg 263(4): 761-777.

18. Lim C, Osseis M, Lahat E (2018) Extracorporeal Pringle Maneuver During Laparoscopic and Robotic Hepatectomy: Detailed Technique and First Comparison with Intracorporeal Maneuver. J Am Coll Surg 226(5): e19-e25.

19. Inoue Y, Suzuki Y, Fujii K (2018) Laparoscopic Hepatic Resection Using Extracorporeal Pringle Maneuver. J Laparoendosc Adv Surg Tech A 2(4)8: 452-458.

20. Rotellar F, Pardo F, Benito A, Martí Cruchaga P, Zozaya G, et al. (2012) A novel extra-glissonian approach for totall laparoscopic left hepatectomy. Surg Endosc 26(9): 2617-2622.

21. Maehara S, Adachi E, Shimada M, Taketomi A, Shirabe K, et al. (2007) Clinical usefulness of biliary scope for Pringle's maneuver in laparoscopic hepatectomy. J Am Coll Surg 205(6): 816-818.

22. Cho A, Yamamoto H, Nagata M, Takiguchi N, Shimada H, et al. (2009) Safe and feasible inflow occlusion in laparoscopic liver resection. Surg Endosc 23(4): 906-908.

23. Dua MM, Worhunsky DJ, Hwa K (2015) Extracorporeal Pringle for laparoscopic liver resection. Surg Endosc 29(6): 1348-1355.

24. Simon J, Meilinger M, Lang H, Hautmann RE, De Petriconi R (2008) Novel technique for in situ cold perfusion in laparoscopic partial nephrectomy. Surg Endosc 22(10): 2184-2189.

25. Le B, Matulewicz RS, Eaton S, Perry K, Nadler RB (2013) Comparative analysis of vascular bulldog clamps used in robot-assisted partial nephrectomy. J Endourol 27(11): 1349-1353.

26. Yang H, Taejong Song (2018) Temporary Simultaneous 2 Arterial Occlusions during Laparoscopic Management for Cornual Ectopic Pregnancy. J Minim Invasive Gynecol 25(6): 961-962.

27. Kim WJ, Kim KH, Shin MH (2017) Totally laparoscopic anatomical liver resection for centrally located tumors: A single center experience. Medicine (Baltimore) 96(4): e5560. 
28. Jiang GQ, Chen P, Qian JJ, Yao J, Wang XD, et al. (2014) Perioperative advantages of modified laparoscopic vs open splenectomy and azygoportal disconnection. World J Gas-troenterol 20(27): 9146-9153.

29. Piardi T, Lhuaire M, Memeo R, Pessaux P, Kianmanesh R, et al. (2016) Laparoscopic Pringle maneuver: how we do it? Hepatobiliary Surg Nutr 5(4): 345-349.

ISSN: 2574-1241

DOI: $10.26717 /$ BJSTR.2020.28.004718

Hui Hou, Xiaoping Geng. Biomed J Sci \& Tech Res

(C) (P) This work is licensed under Creative

Submission Link: https://biomedres.us/submit-manuscript.php
30. Arai S, Mizutani T, Sugiyama T (2020) An Experimental Clamping and Cutting Study of Carotid and Intracranial Stents: Preparation for Surgical Rescue in Stent Complications.World Neurosurg 133: e739-e744.

$\begin{array}{ll}\text { BIOMEDICAL } & \text { Assets of Publishing with us } \\ \text { RESEARCHES } & \text { - Global archiving of articles } \\ & \text { - Immediate, unrestricted online access } \\ & \text { - Rigorous Peer Review Process } \\ & \end{array}$

